\title{
Competition Shadow: Anchoring to Fear Versus Hope in Estimating Rivals in Competition
}

\author{
Ehsan Chitsaz', Seyed Mahdi Etemadifard ${ }^{2}$, Somayeh Khoshsoroor ${ }^{3}$, and Liang Dapeng ${ }^{4}$
}

\author{
1 School of Entrepreneurship, University of Tehran, Tehran, Tehran. Iran \\ ${ }^{2}$ School of Sociology, University of Tehran: Tehran, Tehran, Iran \\ ${ }^{3}$ School of Management, Harbin Institute of Technology, Harbin, China \\ ${ }^{4}$ School of Economy and Management, Harbin Institute of Technology, Heilongjiang, China
}

\section{KEYWORDS}

fear

hope

rival estimation

trait anxiety

rivalry

decision making

\begin{abstract}
We studied the effect of two inconsistent emotions, fear and hope, in strategic decision-making during a competition. We sought to examine which emotion will be more related to whether decision-makers accurately and objectively estimate their rival We developed a nuanced perspective on the effects of trait anxiety on rival estimation by integrating it with the competition shadow. Using a competition simulation and basing on data from 221 individuals across two countries, we found support for a predicted effect of trait anxiety on rival estimation. Several theoretical implications are discussed.
\end{abstract}

\section{INTRODUCTION}

Innovation is an innately uncertain phenomenon (Boudreau et al., 2011), which likewise makes entrepreneurship an uncertain process. Although nobody would like to announce their innovation failures, reports show that more than $80 \%$ of new products fail (Baxter, 2018). In such a situation, how do strategic decision-makers figure out their rivals future performance? When there is no information about future innovation projects as well as their performance, do they estimate their rivals performance as better than their own or do they plan based on their rivals' failures in achieving their goals? It is a vital question when developing strategies for teams as well as companies. To understand this phenomenon, we employed the anchoring bias (Bodenhausen et al., 2000; Lieder et al., 2018a) because, during decision making, a team member relies on an initial piece of data to make judgments. The dynamic nature of anchoring theory is also useful as strategic teams typically face the difficulty in a lack of enough data. According to the anchoring bias, those objects close the anchor are likely to be assimilated toward it, and those further away tend to take over from it in the other direction. Once the anchor value is posited, all following arguments, estimates, and attitudes are determined with the anchor. As Lieder et al. (2018b) report, anchoring occurs when interpreting future informa- tion. We were interested in the emotional dynamics involved in the strategic decision to adopt a reference point in the form of an anchor. The growing field of affect in innovation, as well as entrepreneurship, has shown that emotions are essential in decision-making (Bechara et al., 2000; Chitsaz et al., 2019; Khoshsoroor et al. , 2019). Given the robust evidence that emotions are strongly felt as a consequence of competition (Skinner \& Brewer, 2004), we predicted that emotions are a critical antecedent to the decision to estimate rival performance.

We synthesized the emotions of hope and fear to create the emotional dynamics of competition, called the competition shadow. We focused on the effects of trait anxiety and competition shadow because, compared to other emotions, anxiety and competition shadow are more associated with uncertainty (Calvo \& Dolores Castillo, 2001; Grupe \& Nitschke, 2013), which is inherent in the decision to anchor a reference point. We set the individual as the unit of analysis because

Corresponding author: Ehsan Chitsaz, School of Entrepreneurship, University of Tehran, Tehran, Tehran. Iran. E-mail: chitsaz@ut.ac.ir ; Seyed Mahdi Etemadifard, School of Sociology, University of Tehran: Tehran, Tehran, Iran. E-mail: etemady@ut.ac.ir 
individuals often establish and manage new ventures (Sarason et al., 2006), and make many significant estimations about known and unknown rivals (Kauppila et al., 2018). This research has focused on the individual- rather than the group-level stimulus of rival estimation.

Our primary aim involved understanding the simultaneous effects of trait anxiety and competition shadow. Research has reported that contrasting emotions can be felt in concert in the context of competition (Larsen \& McGraw, 2011; Russell, 2017) and can lead to different behavioral consequences (Schneider \& Schwarz, 2017). The hope and fear in a competition is the result of the importance and uncertainty of outcomes. The influence of hope and fear has also been vigorously played against each other in our daily life as well as in technological venture management (Cacciotti et al., 2016; Martens et al.1995), strategic decision making (Khatri \& Ng, 2000), and political negotiations (Lake \& Rothchild, 1996). However, no prior academic research has examined their combined effects in business contexts. Therefore, how is rival performance predicted when individuals feel both fear and hope at the same time? We developed and tested hypotheses regarding the consequences of the competition shadow for the estimation of rival performance.

As entrepreneurs invest both money and time, effort, and attention in their companies (Cardon \& Kirk, 2015), we examined the competition shadow as a predictor of rival estimation. Furthermore, since personality traits influence affective processes (Gomez \& Gomez, 2002), we also considered trait anxiety as a predictor.

We employed a comprehensive laboratory experiment to realistically simulate and observe the competition shadow in a competition context. To examine the dynamic essence of competition, we tracked each individual's levels of fear, hope, and trait anxiety across the simulation by creating different levels of importance and uncertainty of outcomes.

The current study thus develops the literature on strategic decisionmaking and entrepreneurial affect (Cardon et al., 2012; Cardon \& Kirk, 2015) by suggesting new insight into the emotional and situational antecedents of this phenomenon and by demonstrating the effect of two emotions, hope and fear, in concert at the decision-making level. Further, we develop the literature on affect in entrepreneurship, innovation, and organization (Wennberg et al., 2010) as well as emotional ambivalence (Fong, 2006; Huang et al., 2018) by examining the interplay and outcomes of opposing emotions in a competition context. Finally, answering the call of affect scholars (Cardon et al., 2012), we introduced an inventive method to create emotions and compare the magnitude of their influence on the rival estimation.

\section{THEORETICAL BACKGROUND}

\section{Rival Estimation and its Emotional Antecedents}

Over the past 40 years, researchers have established how emotions affect decision-making as well as estimations in competition: They reduce the utilization of cue utilization (Easterbrook, 1959; Scherer
\& Oshinsky, 1977), increase discrimination of quantity (Baker et al., 2013), improve the perception of the situation regardless of negative feedback (Staw, 1981), and facilitate coping with conflict (Behrendt \& Ben-Ari, 2012; Marceau et al., 2015) as well as competition neglect (Camerer \& Lovallo, 1999) ${ }^{1}$. A large part of the literature demonstrates that emotions and decision-making are interweaved, including the domain of anchoring effect (Furnham \& Boo, 2011), personality traits (Caputo, 2014), social power (Overbeck \& Droutman, 2013), anger (Tsai \& Young, 2010), and anticipated regret (Hoelzl \& Loewenstein, 2005; Wong \& Kwong, 2007). Emotions can lead to greater selfanchoring while negative affectivity (Bodenhausen et al., 2000) and experienced regret (Sagi, 2006) inhibit self-anchoring.

\section{Mixed Emotions in Organizations and Entrepreneurship}

While most of affect research has primarily focused on the effect of emotions on a given dependent variable for example, people, teams, or organizational outcomes, there is a demand for studying the real interaction of manifold, simultaneous, and even contrasting emotions, including the construct of emotional ambivalence (Rothman \& Melwani, 2017), as well as the subtle differences between multifold emotions and their effects on the decision-making process.

\section{WHICH IS MORE POWERFUL IN RIVAL ESTIMATION: FEAR OR HOPE?}

We suggest a conceptual model in which the competition shadow (fear and hope together) leads to the decision to subjectively estimate a rival's performance. At the same time, rival estimation is under the control of trait anxiety. We focus on the comparative influence of competition shadow because uncertainty, as well as importance, which is inherent to the estimation decision, causes fear and hope. Emotion appraisal theory (Jarymowicz \& Bar-Tal, 2006; Lerner \& Keltner, 2000) and prototype emotions theory (Panksepp \& Watt, 2011; Shaver et al., 1987) assume that hope will decrease rival estimation, while fear will promote the likelihood of rival performance.

Individuals can and do feel different emotions at the same instant (Berrios et al., 2015). Our primary research question, therefore, is as follows: Which emotion will have a more significant influence on an individual's decision to estimate their rival's performance positively or negatively, hope, or competition shadow (both fear and hope together)? While there is a convincing theoretical argument that competition shadow has a strong influence, there is little empirical evidence comparing their effects through a nuanced manipulation of fear and hope. We also propose that trait anxiety will operate as a personality variable in estimating rival performance.

\section{Fear and Promoting Rival Estimation}

In the current study, we focus on the fear of financial consequences. We propose that fear of losing money will cause people to predict the rival's performance as better based on the theory that fear is a predictor of 
emotions relevant to the behavioral inhibition system, which is linked to avoidance behaviors (Berrios et al., 2015). Fear is activated by an uncertain future as well as the context of high importance, eliciting a search for information that supports the emotion (Cohen et al., 2014), rumination about unwanted outcomes (Ortony et al., 1988; Roseman, 1996), the belief of winning in the competition with the rival (Elliot \& Church, 1997), and assuming a losing position against the rival due to anchoring effect.

From the perspective of the emotion appraisal theory (Smith \& Ellsworth, 1985), fear involves the perception that the situation (i.e., competition shadow due to external factors) has a more considerable influence on outcome than the individual (i.e., internal factors; Lerner \& Keltner, 2001). Fear evokes feelings of weakness and helplessness about a future event (Shaver et al., 1987) as well as an overestimation of the likelihood of a bad outcome (Bar-Tal, 2007) or the amount of risk inherent in the situation (Khoshsoroor et al., 2017; Lerner \& Keltner, 2001). For example, in two empirical studies of entrepreneurial action, greater fear of failure was associated with less favourable evaluations of entrepreneurial opportunities and a lower tendency to exploit those opportunities (Welpe et al., 2012). This supports the idea that fear of losing increases one's risk perception and, consequently, increases the estimation of a rival's performance (Tsai \& Young, 2010) due to the anchoring effect of own feeling.

From the perspective of cognitive bias (Kahneman \& Klein, 2009), when a question is complicated and an appropriate answer is not available, intuition may still provide a swift answer-but not to the original question. For example, an executive manager may face the question "Did my company's rivals perform better than my company?" Because this question is difficult to answer due to a lack of information on the rivals' recent activity and performance, the answer to a related but more straightforward question, "Did I perform well?" comes easily to the executive's mind. This is the essence of intuitive heuristics. In Kahneman's (2011) words, "when faced with a difficult question, we often answer an easier one instead, usually without noticing the substitution, as a consequence of nonconsciousness thinking" (p. 16). Similarly, people estimate themselves to be below average in a difficult cognitive task when given imperfect information about their rivals (Moore \& Small, 2007). This assumption is compatible with the findings reported in classical studies (Greve \& Kim, 2013; Khoshsoroor et al., 2016), demonstrating that possessing more information about a focal assumption and less information about a rival assumption leads to prior beliefs, which are inconsistent with the focal assumption. Decision-makers who realize that their capability to capture all environmental opportunities in a competitive setting is insufficient are subject to estimate their rivals' performance as higher than their own, as they possess more information about themselves than about others. In this case, the anchoring effect leads to a higher estimation of rival performance.

Because fear increases alertness to threat (Roseman, 2001) and the readiness to protect oneself by averting or avoiding bad situations (Frijda et al., 1989), individuals that are more fearful of losing are assumed to be more likely to make higher estimations of their rival.

\section{Hope and Inhibiting High Rival Estimation}

Hope is a prevenient emotion involving the feeling that a negative condition can be altered shortly (Roseman, 1996). In the current study, we focused on hope for the ultimate success of a venture, related to overcoming a negative financial situation. This mirrors our conceptualization of fear of failure, which entails negative financial consequences. Hope is generally experienced in negative situations (Bryant \& Cvengros, 2004). It also decreases estimations of the rivals' performance.

Discrete emotion theorists have shown that hope influences the evaluation of the probability and desirability of future events and can drive behavior (Ortony et al., 1988). Hope can cause negative feedback to be taken much more positively and can promote the perception of success. It is related to a lower perceived entrepreneurial risk (Podoynitsyna et al., 2012), and in the context of the anchoring effect, it leads to a lower estimation of rival performance.

Based on the emotion appraisal theory, it is assumed that hope arises in response to a perceived lack of personal control over an environment or situation (Roseman, 1996), which leads to feelings of external uncertainty as well as the sense of importance of outcomes. If everything goes well, there is not much need to hope, but if one does not have control, and there are considerable uncertainty and importance, hope becomes very relevant. Hopeful internal appraisal in the face of external uncertainty engages more significant agentic thinking ("I feel I can do it") and pathway thinking ("I feel I know how to get there"). By integrating emotional appraisal theory with Chitsaz's theory (Chitsaz \& Liang, 2016), we provide insight into how hope can influence rival estimation processes: When people feel more hopeful, they experience a greater sense of subjective internal certainty despite objective external uncertainty. The greater internal agency can lead to lower rival estimation through decreasing motivation and anticipation of excellent performance. This motivation boost is reinforced by the belief that hope itself will lead to better work performance (Peterson \& Byron, 2008). As such, we predicted that more hope will lead to lower rival estimation.

Next, we examine our key research question, which concerns the competition shadow: the combined comparative effect of fear and hope felt simultaneously.

\section{Competition Shadow and Rival Estimation}

The hypothesis that the relationship between fear and rival estimation will be stronger than the relationship between hope and rival estimation is based on an evolutionary perspective: Individuals are more adjusted to negative than positive stimuli, including emotions, because this orientation suggests a better chance for survival (Baumeister et al., 2001). This is because fear helps to be aware of threats and facilitates a faster response (Vuilleumier, 2005). Because people are more attuned to fear and act on it spontaneously, it may have a stronger influence in a stressful context of competition than hope, which is not spontaneous and requires complex processing as it is a cognitive-order 
(attend to fear-related stimuli before other stimuli), more intentional emotion that relies on the ability to imagine a better future outcome (Jarymowicz \& Bar-Tal, 2006).

Fear promotes arousal as well, which can increase the strength of emotion, leading to new, even more intense fear reactions (Lang, 1995). Furthermore, based on the prospect theory, fear will have a more intense relationship with rival estimation due to generating a focus on possible losses (Camerer \& Lovallo, 1999; Kahneman \& Tversky, 1979) and the psychological cost of losses is much higher than the psychological benefit of equivalent gains.

To put it another way, better-than-average effects (Larwood \& Whittaker, 1977), comparative-optimism effects (Edwards et al., 2006), positive illusions superiority bias, leniency error (Smith-Crowe et al., 2014), and sense of relative superiority may cause people to cling to overly positive beliefs about themselves, illusions of control, and beliefs that could lead to a lower rival estimation. However, some psychologists have observed that uncertain situations of importance are threatening, and if the appropriate response is immediately available, distress or guilt may occur, which is inconsistent with holding a positive belief about the self in competition. Based on the cognitive dissonance theory (Festinger, 1962), most people are motivated to justify their own beliefs and feelings. Cognitive dissonance is a state of psychological tension that occurs whenever an individual simultaneously holds two cognitions, for example, ideas, attitudes, beliefs, or opinions, that are psychologically inconsistent. In a real situation, holding competition shadow alters one or both cognitions in such a way as to render them more fit with each other or by combining more cognitions that help bridge the gap between the original cognitions. To utilize the anchoring effect, individuals need a reference point, while an evolutionary perspective gives us the reference point by prioritizing negative stimuli over positive ones. Therefore, we can conclude that:

H1: Higher competition shadow will increase rival estimation during competition.

We also propose that trait anxiety will influence rival estimation. We focused on this construct because it is inherently affective, and personality has a significant influence on decision-making and evaluations of environment. Anxiety can narrow the attention span and perception and reduce cognitive flexibility. For example, anxious athletes are likely to worry about things going wrong. Researchers believe that anxious athletes often confuse something "possible" with something "likely to happen" due to a lack of cognitive flexibility and an inability to view the situation in a balanced way during challenging tasks.

The threat of negative results or underperformance can affect anxious individuals at every stage of competition, from appraising the environment to making and implementing decisions, and this is a reference point for the anchoring effect. Researchers discussed the effects of anxiety on the processing of threatening information in some detail (Bijsterbosch et al., 2015). They asserted that high trait anxiety increases one's tendency to direct one's attention to threats, whereas low trait anxiety is associated with the tendency to direct one's atten- tion away from threats. Highly anxious individuals tend to exaggerate the threat posed by information, whereas individuals with low anxiety minimize threats (Nelson et al., 2015). Individuals with high trait anxiety devalue their own performance, which in turn amplifies their estimation of rival performance. Accordingly, we can conclude that:

Hypothesis 2 (H2). Higher trait anxiety will increase rival estimation during a difficult cognitive task.

\section{STUDY 1}

\section{Method}

\section{EXPERIMENTAL METHOD AND DESIGN}

People are often unconscious of the reasons why they act in specific ways or alter their beliefs in one direction or another. Thus, in a complicated situation, simply asking people to explain their behavior will usually not yield reliable results (Powell, 1988). For this reason, we used a quasi-experimental approach to test our hypotheses.

\section{PARTICIPANTS, DESIGN, AND PROCEDURE}

Using an announcement, 289 university students (136 females, 153 male) from China (111 students) and Iran (178 students) were offered the opportunity to compete for a full scholarship for one month (worth CNY 2000 in China and CNY 1650 in Iran). The students completed a trait anxiety questionnaire (Martens et al., 1995) and a social desirability questionnaire (Paulhus, 1984) online in their respective languages. The data provided by eight of the participants were incomplete due to a software setup issue and were thus excluded from subsequent analyses. Sixty participants with high social desirability were eliminated from the data set, leaving 221 students (114 females and 107 males), each of whom participated in five practice rounds to familiarize themselves with the experimental task (a computer game). Participants were assigned randomly to conditions in a $3 \times 3$ factorial experimental design, with importance and uncertainty of outcome as the variables facilitating fear and hope. The importance of outcome was divided into the following three levels: (a) "sandwich": the participant with the highest performance receives a sandwich; (b) "full scholarship": the participant with the highest performance receives a full month's scholarship; and (c) "survival": each participant pays a certain sum to enter the competition (CNY 100 in China/CNY 85 in Iran), and the participant with the highest performance receives a full month's scholarship, whereas all others lose their initial stake. The participants were instructed that they would compete against other participants based on their relative performance in the fifth practice round. The uncertainty of outcome was divided into the following three levels: (a) "Weaker:" the participants were told that they would compete against a weaker rival, based on average performance in the fifth practice round; (b) "Equal:" the participants were told that they would compete against a rival with an approximately similar ability level; and (c) "Stronger:" the participants were told that they would compete against a rival with more excellent 
capability than their own, based on their performance in the fifth practice round.

Before the actual competition, the participants also completed a fear and hope questionnaire.

After five practice rounds, the participants played the computer game competitively. Immediately afterwards, they answered a questionnaire that required them to estimate their rivals' performance in the game. Finally, the participants were thanked, the performance reports were signed, and the date of the announcement of the winner was set.

Task. To develop a task with a high cognitive workload, we modified the method proposed by McKendrick et al. (2013). We set up a series of desktop computers (21 in. monitors, Windows XP) running Aptima's Dynamic Distributed Decision-making (DDD) 4.2 distributed client simulation server, which was programmed as an air-defense environment (see Figure 1). Each participant was responsible for eight unmanned aerial vehicles (UAVs) inside a "red zone," which was attacked by enemy UAVs and numerous neutral UAVs from several points. A "yellow zone" demarcated the area of defensive responsibility held by a "teammate" (a simulated agent, in this case). The subjects were required to complete the following three tasks during each simulation run: (a) use their UAVs to attack enemy UAVs and prevent them from entering the red zone; (b) protect their own UAVs from damage and destruction (via friendly fire or enemy attacks); and (c) send messages to their virtual teammates to warn them of the presence of enemy UAVs in the yellow zone. Four hundred enemy UAVs were programmed to penetrate the battle environment and enter the red zone during a single simulation run (6.5 min per participant). The number of enemy UAVs exceeded the individuals' cognitive load providing frequent loss of opportunity for participants.

At the beginning of the competition, the participants were trained using a PowerPoint presentation that provided instructions on operating the DDD simulation and carrying out the required tasks, such as selecting and moving UAV assets, attacking enemy targets, and sending messages to virtual teammates. Finally, the scoring system was explained, as detailed by de Visser et al. (2010).

Measures. Following Vallerand (1989), all questionnaires were translated into Persian and Chinese by two independent bilingual translators in each language. Next, the two versions of each questionnaire were back-translated into English by another two independent translators, and the resulting versions were compared with the original English versions. Items that had been translated identically by the first and second sets of translators, and closely resembled the original English versions when back-translated, were immediately included in the Persian and Chinese questionnaires. The Chinese versions were generally consistent, whereas discrepancies were noted between the translated versions in Persian. As recommended by a fourth translator, two questions were combined to give a single question, and the remaining questions were re-translated by the fourth translator. Finally, the proposed translations were examined by bilingual translators at one of the authors' university to confirm the accuracy of the translations and the comprehensibility of the translated items and instructions.

Competition shadow was determined using three dimensions: fear, hope, and the multiplication of fear and hope ${ }^{2}$.

Fear was measured right after the factorial design using a sevenpoint scale $(1=$ not at all, 7 = very much): "I fear for the failure in the

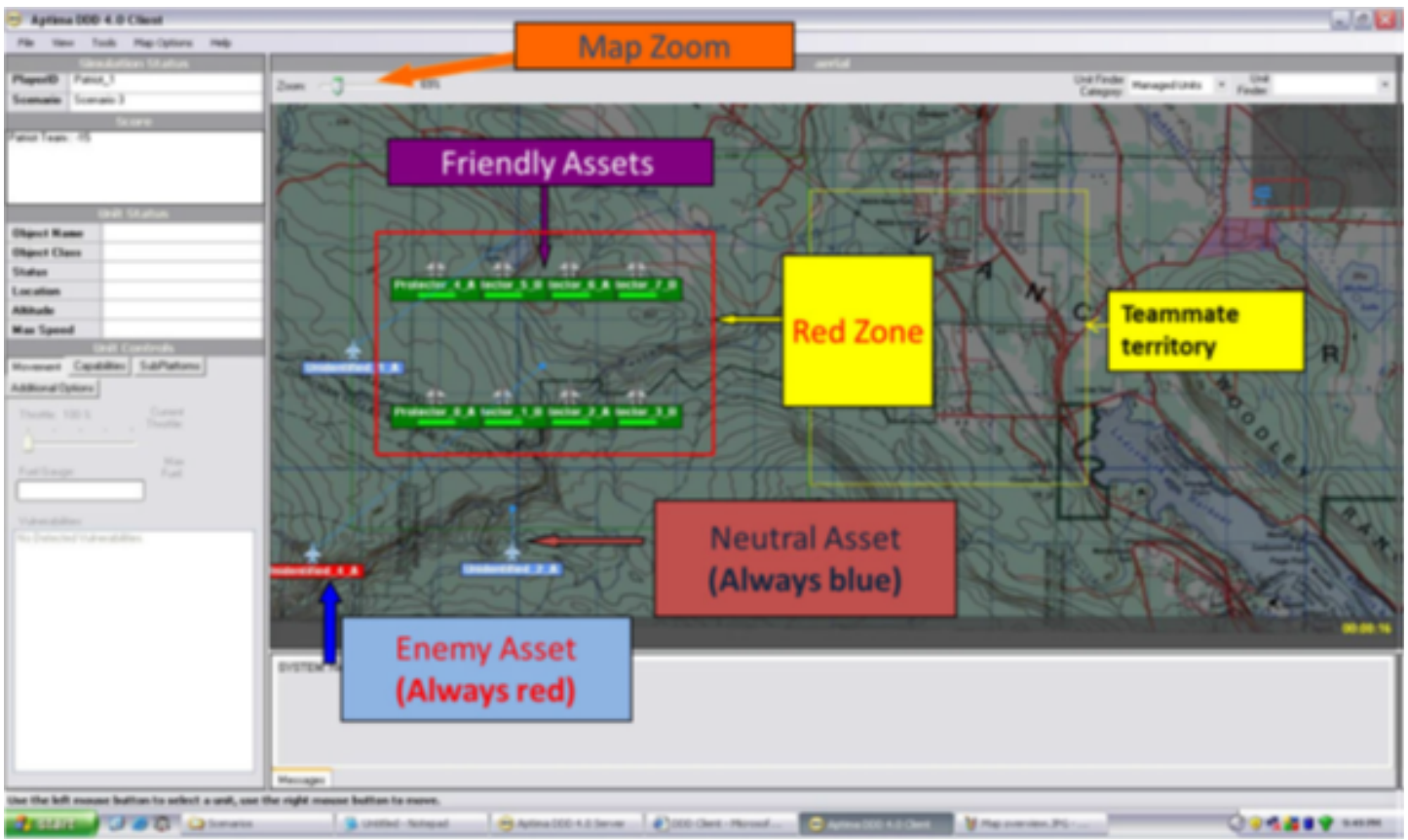

FIGURE 1.

Screen shot of Dynamic Distributed Decision-making (DDD) simulation of air defence task, showing eight friendly assets (green labelled unmanned air vehicles, UAVs) inside the red defensive zone, neutral UAVs (blue labels), enemy UAVs (red labels), and the chat - window at bottom. 
competition," "I am scared of losing money at the end," and "I am worried that I will not reach our goal in the game" (Cronbach's $\alpha=.82$ ).

Hope was also measured right after measuring fear. We chose the most widely used hope scale, Snyder et al.'s (1996) State Hope Scale. We adapted the following three items to the specific context of the simulation using a five-point scale ( $1=$ not at all, 7 = very much): "I feel hopeful that I will succeed in the game," "At present, I am energetically pursuing my goals in the game," and "Right now, I see myself as being quite successful in the game" (Cronbach's $\alpha=.83$ ). We chose Snyder's scale because it is the most frequently cited state hope scale in emotion literature, and because it is a multiple-item scale. However, despite the acceptable Cronbach's $\alpha$, which indicates that the three items were related, we performed a robustness check to ensure that we were indeed capturing the most affective part of hope and conducted all of our analyses using the single item "I feel hopeful that I will succeed in the game." The results of our models remained the same.

Rival estmation was measured in two distinct steps by assessing the participants' estimation of their rivals' ability to win and their estimation of the probability of victory. First, the participants selected one of two mutually exclusive alternatives: their own victory and their rival's victory. Second, they recorded probability judgments on a scale ranging from $50 \%$ to $100 \%$ to indicate the probability of the previous answer. (Probabilities smaller than 50\% were not permitted, because such a judgment would contradict the previous selection of one of the options as correct.)

Planned analysis. Structural equation modelling (SEM) using the partial least squares (PLS) method was used to answer the research questions. In an external model, the PLS analysis is used to estimate the latent variables (LVs) based on the shared variance of the observed variables, using their principal-component weights. The shift in each indicator denotes the extent of its influence on a given $\mathrm{LV}$, resulting in the best possible combination of weights for predicting the LV while accounting for the observed variables.

We assumed that all of the hypothesized relations were linear, and used the SmartPLS software package to test the model using a standard linear PLS analysis. Using WarpPLS (Kock, 2012) and the corresponding guidelines (Kock \& Mayfield, 2015), the quality of the measures was assessed by inspecting item-to-total correlations.
We used the final LVs to calculate the pathways in the inner model and identify significant paths. Due to the nonlinear relationships between the variables addressed in the current study, WarpPLS ${ }^{\text {ma }}$ was used to explicitly identify nonlinear functions connecting pairs of latent variables in the SEM models and to calculate the multivariate coefficients of association accordingly.

\section{RESULTS}

Manipulation check. As expected, the scores for fear at the survival level were higher $(M=6.42)$ than those at the sandwich level $(M$ $=2.10)$ and the scholarship level $(M=4.81) ; F(2,197)=106.655, p$ $<.0001$. Also as expected, the hope scores were higher at the equal level $(M=6.27)$ than at the stronger-rival level $(M=4.35)$ or the weaker-rival level $(M=2.73) ; F(2,197)=83.514, p<.0001$. These results illustrate that the greatest uncertainty was experienced when the participants were competing with rivals at similar ability levels and that the greatest hope was perceived at the survival level. Together, this suggests that the greatest competition shadow is perceived in the condition of competing at the same level performance and investing money to attend the competition.

PLS analysis. The measurement model shows how each block of items relates to its construct or latent variable. The PLS results indicate that a satisfactory level of convergent validity was achieved, based on specific criteria ${ }^{3}$. As shown in Table 1 , all of the item loadings were greater than 0.70 (all significant, $p<0.001$ ). Discriminant validity is verified by measuring the difference between a construct's average variance extracted (AVE) value and its correlations with other constructs. To achieve a sufficiently high level of discriminant validity, the square root of the construct's AVE should be greater than its correlations with all other constructs (Kock, 2012). As shown in Table 3, the threshold for discriminant validity was also exceeded.

Structural model. The hypotheses were evaluated by examining the parameters of the PLS structural model. The R2 values obtained for dependent variables indicate the predictive power of the theoretical model, and standardized path coefficients indicate the power of the relationship between the independent and dependent variables. The results are shown in Figure 2 and Table 2. The R2 value of 0.52 indicates that the theoretical model explained a substantial amount, that is, $52 \%$

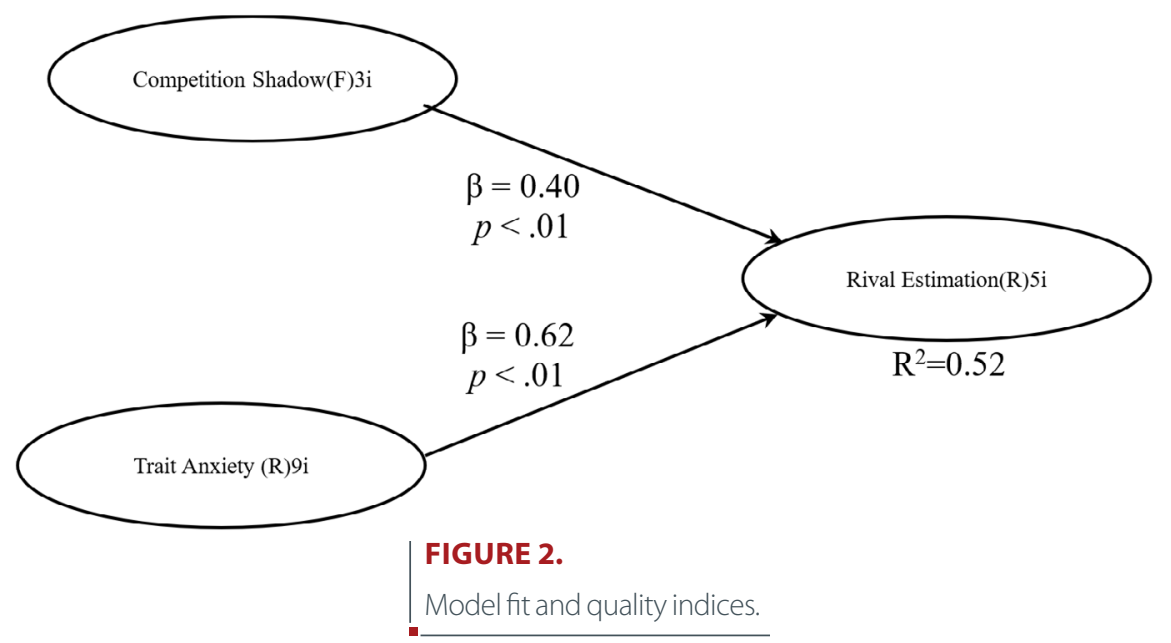




\begin{tabular}{|c|c|c|c|}
\hline Conditions & $\begin{array}{l}\text { Compete against } \\
\text { a weaker rival }\end{array}$ & $\begin{array}{l}\text { Compete against } \\
\text { a rival with an } \\
\text { approximately } \\
\text { similar ability leve }\end{array}$ & $\begin{array}{c}\text { Compete against a rival } \\
\text { with greater capability } \\
\text { than their own }\end{array}$ \\
\hline $\begin{array}{l}\text { Opportunity to win } \\
\text { a sandwich }\end{array}$ & 1 & 2 & 3 \\
\hline $\begin{array}{l}\text { Opportunity to win } \\
\text { a month scholarship }\end{array}$ & 4 & 5 & 6 \\
\hline $\begin{array}{l}\text { Participantpays a } \\
\text { certain sum to enter } \\
\text { the competition }\end{array}$ & 7 & 8 & 9 \\
\hline
\end{tabular}

of the variance in performance. As the R2 of a dependent variable must be at least $10 \%$ to ensure meaningful interpretation, the theoretical model demonstrated substantive explanatory power.

Figure 2 depicts the final structural model. The path coefficients can be taken as standardized $\beta$ weights, each of which was estimated after controlling for the effects of all of the other paths. To determine whether each path was significant, bootstrapping resampling was performed. The PLS parameters of a series of random subsamples of the total sample were repeatedly tested until significance could be estimated from the convergent findings.

Our structural model can be generalized by noting the following significant direct effects of the LVs. Both competition shadow $(\beta=0.62$, $p<.001)$ and trait anxiety $(\beta=0.4, p<.001)$ predicted rival estimation.

As shown in Figure 2 and Tables $4-6$, the results suggest that competition shadow is the most crucial predictor of rival estimation (37\%) in terms of both status and quality, compared with trait anxiety (14.5\%). Our results show that rival estimation is positively related to competition shadow $(p<.001)$, supporting H1. We also found support for $\mathrm{H} 2(p<.001)$, according to which trait anxiety is positively related to rival estimation.

Managerial implications. In this study, we attempted to determine which personality trait and competition shadow variables have the most crucial influence on rival estimation in a cognitive task. The standardized path coefficient estimates displayed in Figure 2 indicate that trait anxiety and competition shadow had different effects on rival estimation. As competition shadow has a larger standard coefficient estimate than trait anxiety, it played a more important role in ensuring a high level of rival estimation.

The experimental results also reveal differences in the influence of the variables on rival estimation, with the following order of importance: competition shadow $(0.371)$ and trait anxiety $(0.145)$. Note that the coefficient for competition shadow is 2.55 times greater than that for trait anxiety, indicating that competition shadow is a better predictor of rival estimation by more than two times. This is indicative of the perception of uncertainty, and as we found before, companies with product similarities have a significant effect on predicting higher rival performance.

\section{STUDY 2}

To facilitate the translation of the model into practical predictions about competition shadow and its relationship with rival estimation, we conducted a real business case study. Using a real recruitment advertisement on three websites, 149 candidates (94 female and 55 male) were registered for eight positions (either permanent or temporary) for an IT company in China. The candidates completed a trait anxiety questionnaire (Martens et al., 1995), a Big Five personality trait questionnaire, and a social desirability questionnaire (Paulhus, 1984) online in Chinese, and then submitted their Curriculum Vitae in their format. The interviewers excluded people who had five years of experience in a related job, expected to be recalled to their previous job, showed any apparent symptoms of mental illness, or reported being unemployed for more than six months. The reason for the last criterion was that the study focused on preventive intervention and was not designed to deal with potential problems of learned helplessness or pessimism among the long-term unemployed.

After a week, the participants were informed of passing the first round. They were randomly assigned to conditions in a $2 \times 2$ factorial experimental design, with importance and uncertainty of outcome as dimensions of competition shadow. Then, date and time were assigned to each participant from 2 to 8 days after the call. The importance of outcome factor had the following two levels: (a) "low importance": participants were informed, "together with hundreds of other applications, your case is under consideration for a part-time job with a minimum payment of 1000 CNY per month." and (b) "high importance": participants were informed "together with hundreds of other applications, your case is under consideration for a full-time job with a minimum payment of $4500 \mathrm{CNY}$ per month."

To evoke a range of responses and to evaluate their determinants, we developed two scenarios for the participants' consideration. In both scenarios, a list of criteria ${ }^{4}$ was presented to the participants and they were informed "this is the evaluation of the recruitment team based on the information you provided. Our company wants the most qualified person available; we do not want someone who will misrepresent our organization and its values. We are evaluating you in different ways, and this is an opportunity to gain the best evaluation you deserve." Then, the participants were given a score transcript. In the first scenario, "low uncertainty of outcome," four out of six criteria on the transcript were randomly determined as "lower than average," while the rest remained "better than average." This minimized the participants' fear about whether the perception of success is positive. In the second scenario, "high uncertainty of outcome", three out of six criteria on the transcript were randomly determined as "lower than average," while the rest remained "better than average." This case maximized the participant's fear about whether the perception of success is positive or not. In both conditions, "capabilities" remained "better than average" to prevent self-distraction during the interview.

During the interview, six participants (two female and four male) decided to leave the interview and gave up these positions. Before the 


\begin{tabular}{|c|c|c|c|c|c|c|}
\hline & $\begin{array}{c}\text { Trait } \\
\text { anxiety }\end{array}$ & $\begin{array}{l}\text { Competition } \\
\text { shadow }\end{array}$ & $\begin{array}{c}\text { Rival } \\
\text { estimation }\end{array}$ & Type & $S E$ & $p$ \\
\hline Trait1 & 0.815 & -0.094 & -0.009 & Reflect & 0.06 & $<.001$ \\
\hline Trait2 & 0.845 & 0.096 & -0.105 & Reflect & 0.06 & $<.001$ \\
\hline Trait3 & 0.859 & 0.023 & 0.003 & Reflect & 0.06 & $<.001$ \\
\hline Trait4 & 0.807 & 0.076 & -0.026 & Reflect & 0.061 & $<.001$ \\
\hline Trait5 & 0.868 & -0.076 & 0.037 & Reflect & 0.06 & $<.001$ \\
\hline Trait6 & 0.845 & 0.026 & -0.01 & Reflect & 0.06 & $<.001$ \\
\hline Trait7 & 0.843 & -0.036 & 0.062 & Reflect & 0.06 & $<.001$ \\
\hline Trait8 & 0.852 & 0.054 & -0.032 & Reflect & 0.06 & $<.001$ \\
\hline Trait9 & 0.857 & -0.067 & 0.077 & Reflect & 0.06 & $<.001$ \\
\hline Fear & 0.036 & 0.669 & -0.111 & Formation & 0.062 & $<.001$ \\
\hline Hope & -0.061 & 0.686 & 0.142 & Formation & 0.062 & $<.001$ \\
\hline Hope $\times$ Fear & 0.018 & 0.984 & -0.024 & Formation & 0.059 & $<.001$ \\
\hline REstim1 & 0.093 & 0.077 & 0.937 & Reflect & 0.059 & $<.001$ \\
\hline REstim2 & -0.048 & -0.01 & 0.931 & Reflect & 0.059 & $<.001$ \\
\hline REstim3 & -0.098 & -0.058 & 0.936 & Reflect & 0.059 & $<.001$ \\
\hline REstim4 & 0.022 & 0.002 & 0.932 & Reflect & 0.059 & $<.001$ \\
\hline REstim5 & 0.032 & -0.012 & 0.911 & Reflect & 0.059 & $<.001$ \\
\hline
\end{tabular}

Note. Factor loadings greater than 0.40 are marked in bold.

TABLE 3.

Correlations Among Latent Variables With Square Roots of Average Variance Extracted, Latent Variable Correlations Window

\begin{tabular}{lccc}
\hline & $\begin{array}{c}\text { Trait } \\
\text { anxiety }\end{array}$ & $\begin{array}{c}\text { Competition } \\
\text { shadow }\end{array}$ & $\begin{array}{c}\text { Rival } \\
\text { estimation }\end{array}$ \\
\hline Trait Anxiety & 0.844 & -0.014 & 0.359 \\
Competition Shadow & -0.014 & 0.793 & 0.583 \\
Rival Estimation & 0.359 & 0.583 & 0.929 \\
R-squared coefficients & & & 0.516 \\
Adjusted R-squared coefficients & & & 0.511 \\
Composite reliability coefficients & 0.957 & 0.831 & 0.969 \\
Average variances extracted & 0.712 & 0.629 & 0.864 \\
Full collinearity VIFs & 1.257 & 1.657 & 1.902 \\
Q- squared coefficients & & & 0.521 \\
\hline Minimum and maximum values & -1.627 & -1.669 & -2.848 \\
\hline Medians (top) and modes (bottom) & 1.774 & 2.349 & 2.301 \\
\hline Skewness (top) and exc. kurtosis & 0.057 & -0.203 & 0.04 \\
(bottom) coefficients & 1.255 & -0.413 & 0.585 \\
\hline & -1.154 & -0.319 & 0.712 \\
\hline
\end{tabular}

\begin{tabular}{cccc} 
& $\begin{array}{l}\text { TABLE 4. } \\
\text { Path Coefficients }\end{array}$ & \\
\hline & $\begin{array}{c}\text { Trait } \\
\text { anxiety }\end{array}$ & $\begin{array}{c}\text { Competition } \\
\text { Shadow }\end{array}$ & $\begin{array}{c}\text { Rival } \\
\text { estimation }\end{array}$ \\
\hline Rival estimation & $0.396^{*}$ & $0.619^{*}$ & \\
\hline & ${ }^{*} p<.001$ &
\end{tabular}




\begin{tabular}{lccc}
\hline $\begin{array}{l}\text { TABLE 5. } \\
\text { Effect Sizes for Path Coefficients }\end{array}$ \\
\hline & $\begin{array}{c}\text { Trait } \\
\text { anxiety }\end{array}$ & $\begin{array}{c}\text { Competition } \\
\text { Shadow }\end{array}$ & $\begin{array}{c}\text { Rival } \\
\text { estimation }\end{array}$ \\
\hline Rival estimation & $0.145^{* *}$ & $0.371^{* * *}$ & \\
\hline
\end{tabular}

Note. $^{* *}=$ medium effect, ${ }^{* *}=$ large effect.

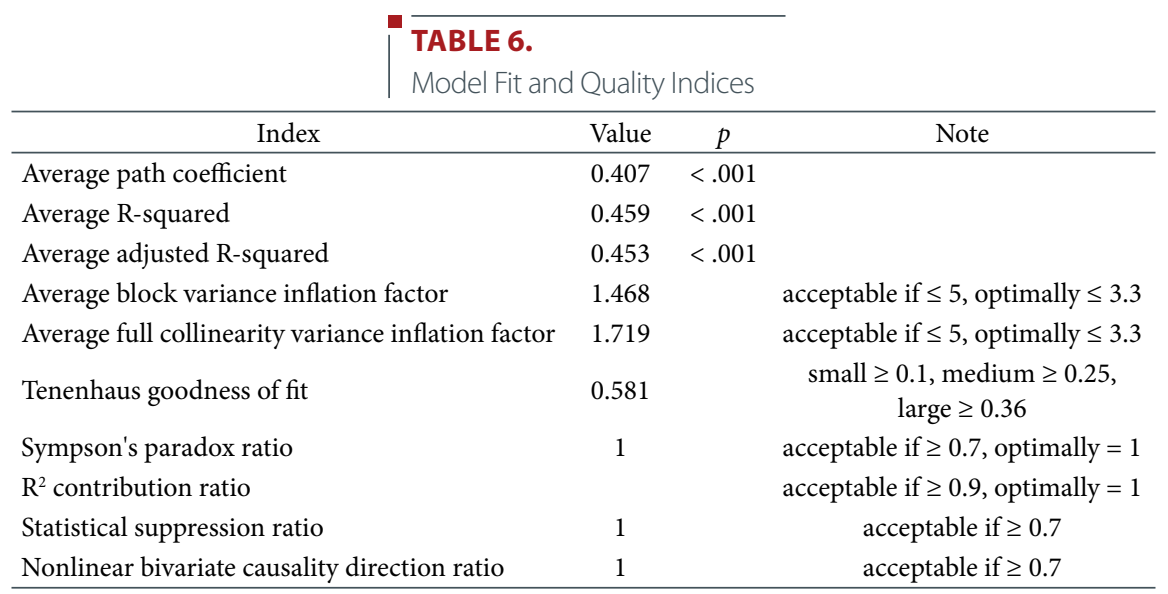

interview, the participants also completed a fear questionnaire and a hope questionnaire.

The interviews included the application of problem-solving and decision-making processes, inoculation against setbacks, computer skills, and two difficult questions on unrelated topics. After filling out a questionnaire that required the participants to estimate their rivals performance in the interview, they were thanked and the date of the announcement of the results was set.

\section{Results}

\section{MANIPULATION CHECK}

As expected, the scores for hope in the high importance of outcome condition were higher $(M[S D]=6.614[0.7669])$ than those at the low importance level $(M[S D]=2.53[1.0812]), F(1,141)=672.344, p<$ $.0001)$. Also as expected, the fear scores were higher in the high uncertainty of outcome $(M[S D]=6.43[0.962])$ than in the low uncertainty of outcome condition $(M[S D]=4.54[0.967]) ; F(1,141)=137.548, p<$ .0001 . These results confirm our findings in Study 1 that the greatest fear was experienced when the participants were competing with rivals at almost similar ability levels. Together, they suggest that the greatest competition shadow is perceived at high hope and high fear.

Although common method factors in exploratory factor analysis are not sufficiently advanced to be used with confidence, the results of collinearity in Study 1 provide enough support for our questionnaire. The results demonstrated that a total of 20 factors were generated under the no-rotation condition, which explained $63.66 \%$ of the variance. The first factor explained $27.63 \%$ of the total variance, which is far less than the criterion of cutoff, which was 50\% (Kock, 2012). This indicated that a common variance did not exist and so the magnitude of the observed relationships in this study did not alter significantly.

\section{DESCRIPTIVE STATISTICS}

Table 7 shows the means and SDs of the variables in Study 2. Each row represents one of the four cells of the factorial design, and the last column shows the statistics for the overall data. Correlations among the variables were presented as part of the basic descriptive statistics. As expected, the hope, fear, trait anxiety, and rival estimation scores were statistically significant when correlated across the three variables. The relationships were positive, with values ranging from .392 to .512 . Note that there were statistically significant positive correlations between hope, fear, and trait anxiety with rival estimation. Table 8 summarizes the pairwise correlations among the variables.

\section{UNIVARIATE ANALYSIS OF VARIANCE AND HYPOTHESIS TESTING}

Univariate analyses of variance (ANOVAs) were conducted to test the main and interaction effects. The results are summarized in Table 9.

\section{MAIN EFFECTS OF HOPE, FEAR, AND TRAIT ANXIETY}

As reported in Table 9, the main effect of hope was significant on rival estimation, $F(2,142)=78.408, p<.01$. Also, the effects of fear, $F(2,142)=6.199, p<.01$, and trait anxiety, $F(7,137)=34.557, p<.01$, on rival estimation were significant.

\section{INTERACTION EFFECTS OF HOPE AND FAER}

As is demonstrated in Table 9, the interaction effects between hope and fear were statistically significant: competition shadow (hope $\times$ 


\begin{tabular}{|c|c|c|c|c|c|}
\hline Hope & Fear & Trait anxiety & $M$ & $S D$ & $N$ \\
\hline \multirow[t]{9}{*}{ High hope } & High fear & High anxiety & 5.8889 & .29283 & 18 \\
\hline & & Low anxiety & 5.1083 & .55944 & 24 \\
\hline & & Total & 5.4429 & .60330 & 42 \\
\hline & Low fear & High anxiety & 5.4889 & .51099 & 9 \\
\hline & & Low anxiety & 4.9368 & .54590 & 19 \\
\hline & & Total & 5.1143 & .58734 & 28 \\
\hline & Total & High anxiety & 5.7556 & .41633 & 27 \\
\hline & & Low anxiety & 5.0326 & .55365 & 43 \\
\hline & & Total & 5.3114 & .61445 & 70 \\
\hline \multirow[t]{9}{*}{ Low hope } & High fear & High anxiety & 4.8400 & .27968 & 10 \\
\hline & & Low anxiety & 4.4788 & .42793 & 17 \\
\hline & & Total & 4.6126 & .41395 & 27 \\
\hline & Low fear & High anxiety & 4.5619 & .43067 & 21 \\
\hline & & Low anxiety & 3.8880 & .31134 & 25 \\
\hline & & Total & 4.1957 & .49931 & 46 \\
\hline & Total & High anxiety & 4.6516 & .40569 & 31 \\
\hline & & Low anxiety & 4.1271 & .46299 & 42 \\
\hline & & Total & 4.3499 & .50870 & 73 \\
\hline \multirow[t]{9}{*}{ Total } & High fear & High anxiety & 5.5143 & .58482 & 28 \\
\hline & & Low anxiety & 4.8473 & .59312 & 41 \\
\hline & & Total & 5.1180 & .67200 & 69 \\
\hline & Low fear & High anxiety & 4.8400 & .62179 & 30 \\
\hline & & Low anxiety & 4.3409 & .67456 & 44 \\
\hline & & Total & 4.5432 & .69461 & 74 \\
\hline & Total & High anxiety & 5.1655 & .68864 & 58 \\
\hline & & Low anxiety & 4.5852 & .68209 & 85 \\
\hline & & Total & 4.8206 & .73983 & 143 \\
\hline
\end{tabular}

\begin{tabular}{|c|c|c|c|c|c|}
\hline & \multicolumn{4}{|c|}{$\begin{array}{l}\text { TABLE } 8 . \\
\text { Correlations Among Variables in Study } 2\end{array}$} & \multirow[b]{2}{*}{ Rival estimation } \\
\hline & & Hope & Fear & Trait anxiety & \\
\hline \multirow{2}{*}{ Hope } & $r$ & 1 & $.179^{\star}$ & -.058 & $.512^{\star *}$ \\
\hline & $p$ & & .032 & .489 & .000 \\
\hline \multirow{2}{*}{ Fear } & $r$ & $.179^{*}$ & 1 & .072 & $.407^{* *}$ \\
\hline & $p$ & .032 & & .390 & .000 \\
\hline \multirow{2}{*}{ Trait anxiety } & $r$ & -.058 & .072 & 1 & $.392^{* *}$ \\
\hline & $p$ & .489 & .390 & & .000 \\
\hline \multirow{2}{*}{ Rival estimation } & $r$ & $.512^{* *}$ & $.407^{* *}$ & $.392^{* *}$ & 1 \\
\hline & $p$ & .000 & .000 & .000 & \\
\hline
\end{tabular}

${ }^{* *} p<.005$ (two-tailed) ${ }^{* *} p<.01$ (two-tailed) 


\begin{tabular}{lccccccc} 
& $\begin{array}{l}\text { TABLE 9. } \\
\text { Univariate Analysis of Variance F Tests Between-Subject Effects }\end{array}$ & & \\
\cline { 2 - 5 } \multicolumn{1}{c}{ Source } & $\begin{array}{c}\text { Type III } \\
\text { sum of } \\
\text { squares }\end{array}$ & $d f$ & $\begin{array}{c}\text { Mean } \\
\text { square }\end{array}$ & $F$ & $p$ & Partial $\eta^{2}$ \\
\hline Corrected model & $23.737 \mathrm{a}$ & 7 & 3.391 & 20.628 & .000 & .517 \\
Intercept & 2700.898 & 1 & 2700.898 & 16429.938 & .000 & .992 \\
Hope & 12.889 & 2 & 12.889 & 78.408 & .000 & .367 \\
Fear & 1.019 & 2 & 1.019 & 6.199 & .010 & .144 \\
Trait Anxiety & 5.681 & 8 & 5.681 & 34.557 & .000 & .204 \\
Competition shadow $($ Hope $\times$ Fear) & .025 & 4 & .025 & .152 & .097 & .201 \\
Competition shadow $\times$ Trait anxiety & .293 & 36 & .293 & 1.784 & .184 & .013 \\
Error & 22.192 & 135 & .164 & & & \\
Total & 3038.780 & 143 & & & & \\
Corrected Total & 45.929 & 142 & & & & \\
\hline
\end{tabular}

$\mathrm{a}=\mathrm{R}^{2}=.517\left(\right.$ Adjusted $\left.\mathrm{R}^{2}=.492\right)$

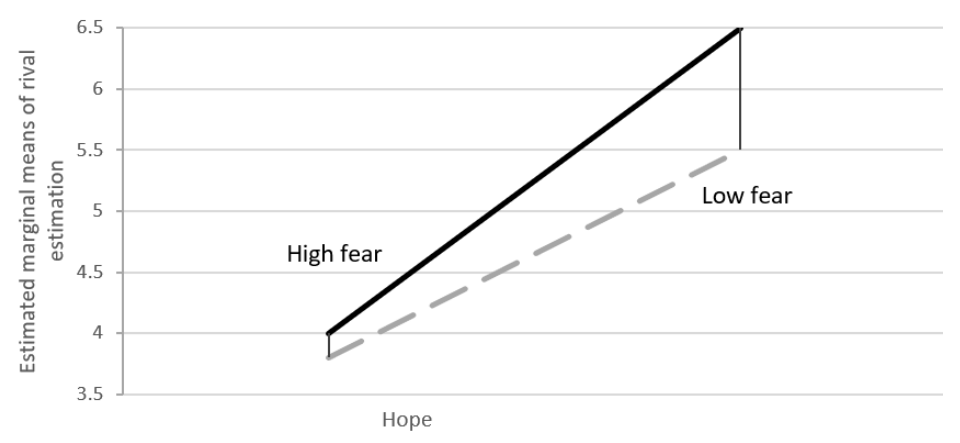

FIGURE 3.

Estimated marginal mean of rival estimation.

fear), $F(4,140)=0.152, p=.697$, and competition shadow $\times$ trait anxiety, $F(1,349)=1.784, p=.184$. However, as Figure 3 demonstrates, the interaction effects for reciprocity between fear and hope were significant for the competition shadow. Thus, the degree of perceived hope moderates the effect of fear on rival estimation. Moreover, the degree of perceived competition shadow moderates the effect of trait anxiety on rival estimation.

Hypotheses 1 and 2 stated that a larger competition shadow and trait anxiety would increase rival estimation during a cognitive task. These results add to our understanding by demonstrating the reciprocal effects of hope on fear, competition shadow, and trait anxiety on rival estimation.

\section{DISCUSSION}

Our main goal was to understand which emotion-fear or hope-had a greater dynamic effect on rival estimation? We found that fear "defeated" hope. Individuals' levels of fear-more than their hope-determined how they estimated their rivals' performance. In other words, their feelings about their own performance drove their decision about their rivals' performance in the future.

We contribute to the literature on emotions in entrepreneurship (Delgado García et al., 2015) by expanding the understanding of the emotional antecedents of competition shadow and rival estimation. First, we presented two conflicting emotions that are very likely to arise in situations of competition but are understudied in a venture exit: fear that the financial situation will worsen and hope that it will improve. Second, through the dynamic lens of rival estimation, we illustrated the tension of experiencing these two emotions at the same time. In simple terms, our new message to the strategic management literature is that during rival estimation, the fear individual feels about the possibility of failure will outweigh their hope of future success.

Third, we also contribute to the strategic management literature. Due to the importance of both fear and hope for predicting rival performance and their opposite natures, understanding which emotion is stronger directs the attention to the influence of affect on rival estimation (e.g., Trigeorgis \& Reuer, 2017; Wong \& Kwong, 2007). Additionally, we introduced a prospective, more agentic approach to rival estimation. 
We also contribute to emotion research in entrepreneurship (Cardon et al., 2012) and other types of organizations (Kilduff et al., 2010). First, we extend the knowledge of how multiple conflicting emotions-fear and hope-collectively influence important strategic decisions, such as estimating rivals or terminating versus escalating commitment to failing ventures. As we have illustrated, individuals do not necessarily feel one emotion at a time; they can feel multiple, often conflicting emotions. The concurrent effect of multiple distinct emotions is an essential area for further investigation in the literature on emotions in organizations (Chitsaz et al., 2017; Larsen \& McGraw, 2011) and entrepreneurship (Cardon et al., 2012; Khoshsoroor et al., 2019). Our study advances understanding in this area. While we did not focus on the general feeling of ambivalence (Rothman \& Melwani, 2017), but instead on the behavioral and psychological outcomes that arise from each of the two different emotions, our research has implications for the emotional ambivalence literature. For example, Rothman and Melwani (2017), in a conceptual article, proposed that leaders' experience of emotional ambivalence would make them more cognitively and behaviorally flexible and open to changes, and as a result, prevent them from escalating commitment to a failing course of action. In our case, by breaking down the generalized psychological construct of emotional ambivalence into specific parts and then examining how each emotion operates in the presence of the other, we contribute to the theorizing about emotional ambivalence in a different way. We found that people are pulled in opposite directions as a result of these opposing emotions and our study offers insight into which of these two specific ambivalent emotions have the most sway on the direction of rival estimation.

Numerous management and psychology researchers have examined factors that compel executives to take (or avoid) risks, such as anxiety (Broman-Fulks et al., 2014). We demonstrated that competition shadow could directly affect strategic risk-taking by influencing rival estimation. We contributed to the literature on equivocal risk-taking by identifying competition shadow as two significant factors predicting individuals' comparative judgment.

Another novel contribution of our study is the finding that executive compensation partly determines the level of perceived competition shadow by changing the intrinsic and extrinsic importance of a decision. The findings of many studies suggest that executive stock options increase risk-taking (Baixauli-Soler et al., 2015), yet scholars have also argued that the effects of incentives vary depending on the attributes of the executives themselves (Wowak \& Hambrick, 2010). Our findings suggest that stock options may increase perceived competition shadow and that the combined effect of large competition shadow and a highly anxious personality may increase rival estimation when making strategic cognitive decisions.

According to the intentional-style theory, higher anxiety increases internal focus and reduces attentional cognitive breadth. Consistent with this theory, our results demonstrate that an increase in anxiety associated with cognitive bias (high rival estimation) experienced by highly anxious individuals significantly impairs performance by inhibiting perceptual processing, attention to threat, decision making, and response production. The combination of a small competition shadow and low trait anxiety also impairs performance due to a lack of arousal (low rival estimation), which prevents individuals from adequately mobilizing their attention and effort.

The attraction of our competition shadow theory lies not only in the preliminary support it received from previous research but also in the fact that it can offer insight into the framing of aspiration in the behavioral theory of the firm-not only when managers make strategic decisions, but also when conflict arises between middle and top managers. The following two conditions psychologically guide the managers of aspirational firms to increase their market share or revenue or otherwise to expand the scope, status, or influence of their organizations within the greater systemic environment. First, low trait anxiety in highly competitive markets, and second, high trait anxiety in relatively uncompetitive markets. While middle managers are likely to be concerned primarily with protecting their firm's market share, other managers, such as those responsible for research and development, are likely to prioritize their organization's developmental needs. Compared with managers with specific roles, high-level managers must consider a broader array of organizational concerns. This plays a vital role in decreasing the perceived importance of a threat (and then increasing hope) and thus the size of the competition shadow cast by the threat. It may also explain why high-level managers often disregard middle managers' recommendations for ensuring firm security.

The results may also suggest that in the presence of a large competition shadow, anxious top executives do not perform to the best of their abilities in cognitive tasks due to the high pressure of extreme rival estimation. Consistent with recent findings, our results illustrate that the greatest competition shadow is perceived at the survival level, when competitors are estimated at equals. As Mannor et al. (2016) concluded, chief executive officers (CEOs) experience greatest anxiety in contexts of loss, suggesting that anxious top managers and a large competition shadow lead to poor firm decisions.

\section{Limitations and Opportunities for Future Research}

Our study has certain limitations. First, we used a student sample and a sample of job candidates, as it would have been too difficult to recruit such a large number of top managers to take part in our study. Nevertheless, the participants' responses shed light on relevant aspects of organizational behavior and strategy. To confirm the generalizability of our findings, future researchers may investigate the role of competition shadow on top managers' anxiety using different sampling and measurement approaches. As we did not examine performance feedback as an antecedent of the value afforded to outcomes, and importance and uncertainty of outcomes accordingly, we were unable to examine the precise mechanism(s) used by anxious top executives to shape their decision teams. Future researchers may investigate changes in the joint effect of competition shadow and competitive trait anxiety as commitment, innovation, and strategy making increase. The findings of our study show that the influence of competition shadow on 
competition and choices is much more significant today than it was before the era of big data.

Lastly, we demonstrated a creative method to capture emotions and compare the magnitude of the influence of competing emotions on actors over time. Researchers of entrepreneurial emotions (Cardon et al., 2012) have called for longitudinal data on emotion dynamics. Our simulation provides such data, offering a novel methodology to dynamically capture emotions in future research.

Although cross-cultural research has confirmed that trait anxiety exists worldwide, the expression, interpretation, and social response to this personality trait varies widely. On the other hand, cultural variations in trait anxiety could lead to variations in rival estimation and, subsequently, in strategic decision making. It would be insightful to decipher the way different nations judge their rivals by evaluating the interactive effects of rival estimation and competition shadow in a cross-cultural study.

Finally, there has been a growing concern about the nature of wellbeing on the part of social psychologists who claim that well-being results from a judgment-based cognitive process of comparison between current conditions and aspirations. As the competition shadow theory demonstrated, rival estimation is a consequence of situational factors and personality traits. Thus, it would be advisable to investigate the effects of competition shadow on well-being as antecedents of competition shadow in entrepreneurship.

\section{FOOTNOTES}

${ }^{1}$ Competition neglect is a known cognitive phenomenon where human agents systematically ignore the effects of competition while forecasting success.

${ }^{2}$ The reciprocal influence of uncertainty of outcomes and its importance has been examined in Study 2.

${ }^{3}$ Convergent validity is generally achieved if the following three criteria are met (Kock, 2012): (a) all item factor loadings are significant and greater than 0.70 , (b) the average variance extracted (AVE, the amount of variance captured by a latent variable relative to the amount caused by measurement error) is greater than 0.50 (or the square root of AVE > 0.707), and (c) the composite reliability index for each construct is greater than 0.80 .

${ }^{4}$ Openness to experience, conscientiousness, extraversion, trait anxiety, related experience, capabilities, and cultural fit.

\section{ACKNOWLEDGEMENTS}

On behalf of all authors, the corresponding author states that there is no conflict of interest.

Financial support for this research project was provided by the China Natural Science Foundation (Award number 71073040, 71273075) and the China Scholarship Council Fund. The content of this paper is solely the responsibility of the authors.

The authors thank Advances in Cognitive Psychology for reviewing and commenting on an early version of this paper.

\section{REFERENCES}

Baixauli-Soler, J. S., Belda-Ruiz, M., \& Sanchez-Marin, G. (2015). Executive stock options, gender diversity in the top management team, and firm risk taking. Journal of Business Research, 68, 451-463.

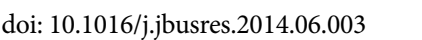

Baker, J., Rodzon, K., \& Jordan, K. (2013). The impact of emotion on numerosity estimation. Frontiers in Psychology, 4, 52. doi: 10.3389/ fpsyg.2013.00521 السلسلسلس

Bar-Tal, D. (2007). Sociopsychological foundations of intractable conflicts. American Behavioral Scientist, 50, 1430-1453. doi: https://journals.sa10.1177/0002764207302462epub.com/doi/

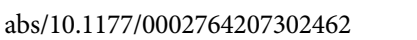

Baumeister, R. F., Bratslavsky, E., Finkenauer, C., \& Vohs, K. D. (2001). Bad is stronger than good. Review of General Psychology, 5, 323-370. doi: 10.1037/1089-2680.5.4.323 سلس

Baxter, M. (2018). Product design. CRC Press.

Bechara, A., Damasio, H., \& Damasio, A. R. (2000). Emotion, decision making and the orbitofrontal cortex. Cerebral Cortex, 10, 295-307. doi: 10.1093/cercor/10.3.295 المالسلسلس

Behrendt, H., \& Ben-Ari, R. (2012). The positive side of negative emotion: The role of guilt and shame in coping with interpersonal conflict. Journal of Conflict Resolution, 56, 1116-1138. doi:

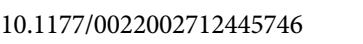

Berrios, R., Totterdell, P., \& Kellett, S. (2015). Investigating goal conflict as a source of mixed emotions. Cognition and Emotion, 29, 755-763.

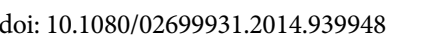

Bijsterbosch, J., Smith, S., \& Bishop, S. J. (2015). Functional connectivity under anticipation of shock: Correlates of trait anxious affect versus induced anxiety. Journal of Cognitive Neuroscience, 27, 1840-1853. doi: 10.1162/jocn_a_00825 الفلسلس

Bodenhausen, G. V., Gabriel, S., \& Lineberger, M. (2000). Sadness and susceptibility to judgmental bias: The case of anchoring. Psychological

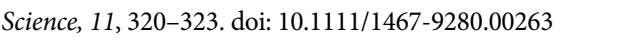

Boudreau, K. J., Lacetera, N., \& Lakhani, K. R. (2011). Incentives and problem uncertainty in innovation contests: An empirical analysis. Management Science, 57, 843-863. doi: 10.1287/mnsc.1110.1322 السلسلس Broman-Fulks, J. J., Urbaniak, A., Bondy, C. L., \& Toomey, K. J. (2014). Anxiety sensitivity and risk-taking behavior. Anxiety, Stress, and Coping, 27, 619-632. doi: 10.1080/10615806.2014.896906 السلسل

Bryant, F. B., \& Cvengros, J. A. (2004). Distinguishing hope and optimism: Two sides of a coin, or two separate coins? Journal of Social and Clinical Psychology, 23, 273-302. doi: 10.1521/

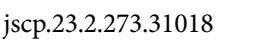

Cacciotti, G., Hayton, J. C., Mitchell, J. R., \& Giazitzoglu, A. (2016). A reconceptualization of fear of failure in entrepreneurship. Journal of Business Venturing, 31, 302-325. doi: 10.1016/j.jbusvent.2016.02.002 |سلس

Calvo, M. G., \& Dolores Castillo, M. (2001). Selective interpretation in anxiety: Uncertainty for threatening events. Cognition \& Emotion, 15, 299-320. doi: 10.1080/02699930126040 الس الس

Camerer, C., \& Lovallo, D. (1999). Overconfidence and excess entry: An experimental approach. The American Economic Review, 89, 


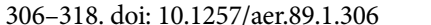

Caputo, A. (2014). Relevant information, personality traits and anchoring effect. International Journal of Management and Decision

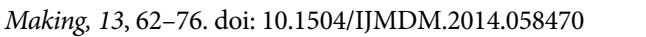

Cardon, M. S., Foo, M. D., Shepherd, D., \& Wiklund, J. (2012). Exploring the heart: Entrepreneurial emotion is a hot topic. Entrepreneurship Theory and Practice, 36, 1-10. doi: 10.1111/j.15406520.2011.00501.x سلس الس

Cardon, M. S., \& Kirk, C. P. (2015). Entrepreneurial passion as mediator of the self-efficacy to persistence relationship. Entrepreneurship Theory and Practice, 39, 1027-1050. doi: 10.1111/etap.12089 المالسلسلسا

Chitsaz, E., \& Liang, D. (2016). The psychology of the competition in hightech industries [Paper presentation]. 8th International Conference on Information Management and Engineering. Istanbul, Turkey.

Chitsaz, E., Liang, D., \& Khoshsoroor, S. (2017). The impact of resource configuration on Iranian technology venture performance. Technological Forecasting and Social Change, 122, 186-195. doi:

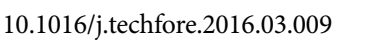

Chitsaz, E., Tajpour, M., Hosseini, E., Khorram, H., \& Zorrieh, S. (2019). The effect of human and social capital on entrepreneurial activities: A case study of Iran and implications. Entrepreneurship and Sustainability Issues, 6, 1193-1203. doi: 10.9770/jesi.2019.6.3(24) (لس

Cohen, S., Halperin, E., Porat, R., \& Bar-Tal, D. (2014). The differential effects of hope and fear on information processing in intractable conflict. Journal of Social and Political Psychology, 2, 11-30. doi: 10.5964/jspp.v2i1.230 الم

Delgado García, J. B., De Quevedo Puente, E., \& Blanco Mazagatos, V. (2015). How affect relates to entrepreneurship: A systematic review of the literature and research agenda. International Journal of Management Reviews, 17, 191-211. doi: 10.1111/ijmr.12058 الس

de Visser, E., Shaw, T., Mohamed-Ameen, A., \& Parasuraman, R. (2010). Modeling human-automation team performance in networked systems: Individual differences in working memory count. Proceedings of the Human Factors and Ergonomics Society Annual Meeting, 54, 1087-1091. doi: 10.1177/154193121005401408 المالسلس

Easterbrook, J. A. (1959). The effect of emotion on cue utilization and the organization of behavior. Psychological Review, 66, 183-201. doi: 10.1037/h0047707 الس الس

Edwards, J. R., Cable, D. M., Williamson, I. O., Lambert, L. S., \& Shipp, A. J. (2006). The phenomenology of fit: linking the person and environment to the subjective experience of person-environment fit. Journal of Applied Psychology, 91, 802-827. doi:10.1037/00219010.91.4.802 السلسلس

Elliot, A. J., \& Church, M. A. (1997). A hierarchical model of approach and avoidance achievement motivation. Journal of Personality and Social Psychology, 72, 218-232. السلسلس

Festinger, L. (1962). A theory of cognitive dissonance (Vol. 2): Stanford University Press.

Fong, C. T. (2006). The effects of emotional ambivalence on creativity. Academy of Management Journal, 49, 1016-1030. doi: 10.5465/ amj.2006.22798182 سلس

Frijda, N. H., Kuipers, P., \& Ter Schure, E. (1989). Relations among emotion, appraisal, and emotional action readiness. Journal of Personality and Social Psychology, 57, 212-228. كلسلسلس

Furnham, A., \& Boo, H. C. (2011). A literature review of the anchoring effect. The Journal of Socio-Economics, 40, 35-42. doi: 10.1016/j. socec.2010.10.008 سلس

Gomez, A., \& Gomez, R. (2002). Personality traits of the behavioural approach and inhibition systems: Associations with processing of emotional stimuli. Personality and Individual Differences, 32, 12991316. doi: 10.1016/S0191-8869(01)00119-2 المبلسلس

Greve, H. R., \& Kim, J.-Y. (2013). Running for the exit: Community cohesion and bank panics. Organization Science, 25, 204-221. doi: 10.1287/orsc.2013.0825 المالسلس

Grupe, D. W., \& Nitschke, J. B. (2013). Uncertainty and anticipation in anxiety: An integrated neurobiological and psychological perspective. Nature Reviews Neuroscience, 14, 488-501. doi: 10.1038/ nrn3524 إلس

Hoelzl, E., \& Loewenstein, G. (2005). Wearing out your shoes to prevent someone else from stepping into them: Anticipated regret and social takeover in sequential decisions. Organizational Behavior and Human Decision Processes, 98, 15-27. doi: 10.1016/j. obhdp.2005.04.004 布

Huang, G.-H., Korfiatis, N., \& Chang, C.-T. (2018). Mobile shopping cart abandonment: The roles of conflicts, ambivalence, and hesitation. Journal of Business Research, 85, 165-174. doi: 10.1016/j.jbusres.2017.12.008 पسلس

Jarymowicz, M., \& Bar-Tal, D. (2006). The dominance of fear over hope in the life of individuals and collectives. European Journal of Social Psychology, 36, 367-392. doi: 10.1002/ejsp.302 سلسلسلس

Kahneman, D. (2011). Thinking, fast and slow. Macmillan.

Kahneman, D., \& Klein, G. (2009). Conditions for intuitive expertise: A failure to disagree. American Psychologist, 64, 515-526. السلسلس

Kahneman, D., \& Tversky, A. (1979). Prospect theory: An analysis of decision under risk. Econometrica: Journal of the Econometric Society, 263-291. doi: 10.1142/9789814417358_0006 المالسلس

Kauppila, O. P., Bizzi, L., \& Obstfeld, D. (2018). Connecting and creating: Tertius iungens, individual creativity, and strategic decision processes. Strategic Management Journal, 39, 697-719. doi: 10.1002/smj.2728 الملسلس Khatri, N., \& Ng, H. A. (2000). The role of intuition in strategic decision making. Human Relations, 53, 57-86. doi:

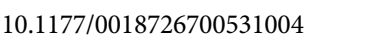

Khoshsoroor, S., Liang, D., \& Chitsaz, E. (2016). Propositions on resource allocation in teams [Paper presentation]. 8th International Conference on Information Management and Engineering. Istanbul, Turkey.

Khoshsoroor, S.,Liang, D., Chitsaz, E., \& Alizadeh, H. (2017). How can risk propensity mediate the effect of trait anxiety on entrapment behavior? [Paper presentation]. International Conference on Business and Information Management. Beijing, China.

Khoshsoroor, S., Liang, D., Salami, G. E., \& Chitsaz, E. (2019). Team cohesion: A double-edged sword in the relationship between rival estimation and escalation of commitment. Social Behavior and Personality: An International Journal, 47, 1-12. doi: 10.2224/ 
sbp.8122 سلس

Kilduff, G. J., Elfenbein, H. A., \& Staw, B. M. (2010). The psychology of rivalry: A relationally dependent analysis of competition. Academy of Management Journal, 53, 943-969. doi: 10.5465/ amj.2010.54533171 سلس

Kock, N. (2012). WarpPLS 5.0 User Manual. http://cits.tamiu.edu/ WarpPLS/UserManual_v_5_0.pdf

Kock, N., \& Mayfield, M. (2015). PLS-based SEM algorithms: The good neighbor assumption, collinearity, and nonlinearity. Information Management and Business Review, 7, 113-130. doi: 10.22610/imbr. v7i2.1146 سلس

Lake, D. A., \& Rothchild, D. (1996). Containing fear: The origins and management of ethnic conflict. International Security, 21, 41-75. doi: $10.1162 /$ isec.21.2.41

Lang, P. J. (1995). The emotion probe: Studies of motivation and attention. American Psychologist, 50, 372-385. الس الس الس

Larsen, J. T., \& McGraw, A. P. (2011). Further evidence for mixed emotions. Journal of Personality and Social Psychology, 100, 1095-1110. doi: $10.1037 / \mathrm{a} 0021846$ سلس

Larwood, L., \& Whittaker, W. (1977). Managerial myopia: Self-serving biases in organizational planning. Journal of Applied Psychology, 62, 194-198. doi: 10.1037/0021-9010.62.2.194 سلس

Lerner, J. S., \& Keltner, D. (2000). Beyond valence: Toward a model of emotion-specific influences on judgement and choice. Cognition

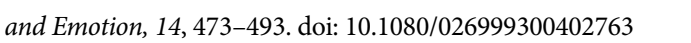

Lerner, J. S., \& Keltner, D. (2001). Fear, anger, and risk. Journal of Personality and Social Psychology, 81, 146-159. doi: 10.1037/0022-

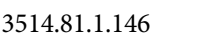

Lieder, F., Griffiths, T. L., Huys, Q. J., \& Goodman, N. D. (2018a). The anchoring bias reflects rational use of cognitive resources. Psychonomic Bulletin and Review, 25, 322-349. doi: 10.3758/s13423017-1286-8 كلس

Lieder, F., Griffiths, T. L., Huys, Q. J., \& Goodman, N. D. (2018b). Empirical evidence for resource-rational anchoring and adjustment. Psychonomic Bulletin and Review, 25, 775-784. doi:10.3758/s13423017-1288-6.

Mannor, M. J., Wowak, A. J., Bartkus, V. O., \& Gomez-Mejia, L. R. (2016). Heavy lies the crown? How job anxiety affects top executive decision making in gain and loss contexts. Strategic Management Journal, 37, 1968-1989. doi: 10.1002/smj.2425 سلسلس

Marceau, K., Zahn-Waxler, C., Shirtcliff, E. A., Schreiber, J. E., Hastings, P., \& Klimes-Dougan, B. (2015). Adolescents', mothers', and fathers' gendered coping strategies during conflict: Youth and parent influences on conflict resolution and psychopathology. Development and Psychopathology, 27, 1025-1044. doi: 10.1017/S0954579415000668 1ل

Martens, R., Vealey, R. S., \& Burton, D. (1995). Competitive anxiety in sport. Human Kinetics.

McKendrick, A. M., \& Battista, J. (2013). Perceptual learning of contour integration is not compromised in the elderly. Journal of Vision,

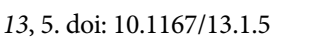

Moore, D. A., \& Small, D. A. (2007). Error and bias in comparative judgment: on being both better and worse than we think we are.
Journal of Personality and Social Psychology, 92, 972-989. doi: 10.1037/0022-3514.92.6.972 الس السلس

Nelson, A. L., Purdon, C., Quigley, L., Carriere, J., \& Smilek, D. (2015). Distinguishing the roles of trait and state anxiety on the nature of anxiety-related attentional biases to threat using a free viewing eye movement paradigm. Cognition and Emotion, 29, 504-526. doi: $10.1080 / 02699931.2014 .922460$ Шلسلس

Ortony, A., Clore, G. L., \& Collins, A. (1988). The cognitive structure of emotions. Cambridge University Press.

Overbeck, J. R., \& Droutman, V. (2013). One for all: Social power increases self-anchoring of traits, attitudes, and emotions. Psychological Science, 24, 1466-1476. doi: 10.1177/0956797612474671 سلس

Panksepp, J., \& Watt, D. (2011). What is basic about basic emotions? Lasting lessons from affective neuroscience. Emotion Review, 3, 387-396. doi: 10.1177/1754073911410741 1لس لسلس

Paulhus, D. L. (1984). Two-component models of socially desirable responding. Journal of Personality and Social Psychology, 46, 598-609. doi: 10.1037/0022-3514.46.3.598 الس الس الس

Peterson, S. J., \& Byron, K. (2008). Exploring the role of hope in job performance: Results from four studies. Journal of Organizational Behavior, 29, 785-803. doi: 10.1002/job.492 السلسلسلس

Podoynitsyna, K., Van der Bij, H., \& Song, M. (2012). The role of mixed emotions in the risk perception of novice and serial entrepreneurs. Entrepreneurship Theory and Practice, 36, 115-140. doi:

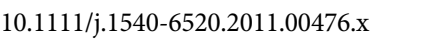

Powell, J. L. (1988). A test of the knew-it-all-along effect in the 1984 presidential and statewide elections. Journal of Applied Social Psychology,

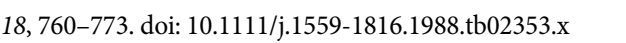

Roseman, I. J. (1996). Appraisal determinants of emotions: Constructing a more accurate and comprehensive theory. Cognition and Emotion, 10, 241-278. doi: 10.1080/026999396380240 السلسلسلس

Roseman, I. J. (2001). A model of appraisal in the emotion system. In K. R. Scherer, A. Schorr, \& T. Johnstone (Eds.), Appraisal processes in emotion: Theory, methods, research (pp. 68-91). Oxford University Press.

Rothman, N. B., \& Melwani, S. (2017). Feeling mixed, ambivalent, and in flux: The social functions of emotional complexity for leaders. Academy of Management Review, 42, 259-282. doi: 10.5465/ amr.2014.0355 سلس

Russell, J. A. (2017). Mixed emotions viewed from the psychological constructionist perspective. Emotion Review, 9, 111-117. doi: 10.1177/1754073916639658 السلسلس

Sagi, J. S. (2006). Anchored preference relations. Journal of Economic Theory, 130, 283-295. doi: 10.1016/j.jet.2005.01.009 السلسلسل

Sarason, Y., Dean, T., \& Dillard, J. F. (2006). Entrepreneurship as the nexus of individual and opportunity: A structuration view. Journal of Business Venturing, 21, 286-305. doi: 10.1016/j.jbusvent.2005.02.007 سلس

Scherer, K. R., \& Oshinsky, J. S. (1977). Cue utilization in emotion attribution from auditory stimuli. Motivation and Emotion, 1, 331-346. السلبل

Schneider, I. K., \& Schwarz, N. (2017). Mixed feelings: The case of ambivalence. Current Opinion in Behavioral Sciences, 15, 39-45. doi: 
10.1016/j.cobeha.2017.05.012 (15)

Shaver, P., Schwartz, J., Kirson, D., \& O'Connor, C. (1987). Emotion knowledge: Further exploration of a prototype approach. Journal of Personality and Social Psychology, 52, 1061-1086. سلس الس الس

Skinner, N., \& Brewer, N. (2004). Adaptive approaches to competition: Challenge appraisals and positive emotion. Journal of Sport and Exercise Psychology, 26, 283-305. doi: 10.1123/jsep.26.2.283 الس السلسل

Smith-Crowe, K., Burke, M. J., Cohen, A., \& Doveh, E. (2014). Statistical significance criteria for the $\mathrm{r}$ WG and average deviation interrater agreement indices. Journal of Applied Psychology, 99, 239-261. المالسلسل|

Smith, C. A., \& Ellsworth, P. C. (1985). Patterns of cognitive appraisal in emotion. Journal of Personality and Social Psychology, 48, 813838. 友

Staw, B. M. (1981). The escalation of commitment to a course of action. Academy of Management Review, 6, 577-587. doi: 10.5465/ amr.1981.4285694 سلس

Snyder, C. R., Sympson, S. C., Ybasco, F. C., Borders, T. F., Babyak, M. A., \& Higgins, R. L. (1996). Development and validation of the State Hope Scale. Journal of Personality and Social Psychology, 70, 321-335. 10.1037/0022-3514.70.2.321 المالسلسال

Trigeorgis, L., \& Reuer, J. J. (2017). Real options theory in strategic management. Strategic Management Journal, 38, 42-63. doi: $10.1002 / \mathrm{smj} .2593$ سلس

Tsai, M.-H., \& Young, M. J. (2010). Anger, fear, and escalation of commitment. Cognition and Emotion, 24, 962-973. doi:

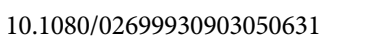

Vallerand, R. J. (1989). Toward a methodology for the transcultural validation of psychological questionnaires-Implications for Studies in the french language. Canadian Psychology-Psychologie Canadienne, 30, 662-680. 10.1037/h0079856 سلس الس

Vuilleumier, P. (2005). How brains beware: Neural mechanisms of emotional attention. Trends in Cognitive Sciences, 9, 585-594. doi: 10.1016/j.tics.2005.10.011 سلس

Welpe, I. M., Spörrle, M., Grichnik, D., Michl, T., \& Audretsch, D. B. (2012). Emotions and opportunities: The interplay of opportunity evaluation, fear, joy, and anger as antecedent of entrepreneurial exploitation. Entrepreneurship Theory and Practice, 36, 69-96. doi: 10.1111/j.1540-6520.2011.00481.x المالسلس

Wennberg, K., Wiklund, J., DeTienne, D. R., \& Cardon, M. S. (2010). Reconceptualizing entrepreneurial exit: Divergent exit routes and their drivers. Journal of Business Venturing, 25, 361-375. doi:10.1016/j.jbusvent.2009.01.001 الس السلسلس

Wong, K. F. E., \& Kwong, J. Y. (2007). The role of anticipated regret in escalation of commitment. Journal of Applied Psychology, 92, 545-554. doi: 10.1037/0021-9010.92.2.545 المالسلس

Wowak, A. J., \& Hambrick, D. C. (2010). A model of person-pay interaction: How executives vary in their responses to compensation arrangements. Strategic Management Journal, 31, 803-821. doi: 10.1002/smj.839 سلس الس 